


\title{
Michel Henry e a noção de arte
}

\author{
Autor(es): Heleno, José Manuel
}

Publicado por: Imprensa da Universidade de Coimbra

URL persistente:

URI:http://hdl.handle.net/10316.2/42840

DOI:

DOI:http://dx.doi.org/10.14195/0872-0851_49_3

Accessed : $\quad$ 26-Apr-2023 03:21:32

A navegação consulta e descarregamento dos títulos inseridos nas Bibliotecas Digitais UC Digitalis, UC Pombalina e UC Impactum, pressupõem a aceitação plena e sem reservas dos Termos e Condições de Uso destas Bibliotecas Digitais, disponíveis em https://digitalis.uc.pt/pt-pt/termos.

Conforme exposto nos referidos Termos e Condições de Uso, o descarregamento de títulos de acesso restrito requer uma licença válida de autorização devendo o utilizador aceder ao(s) documento(s) a partir de um endereço de IP da instituição detentora da supramencionada licença.

Ao utilizador é apenas permitido o descarregamento para uso pessoal, pelo que o emprego do(s) título(s) descarregado(s) para outro fim, designadamente comercial, carece de autorização do respetivo autor ou editor da obra.

Na medida em que todas as obras da UC Digitalis se encontram protegidas pelo Código do Direito de Autor e Direitos Conexos e demais legislação aplicável, toda a cópia, parcial ou total, deste documento, nos casos em que é legalmente admitida, deverá conter ou fazer-se acompanhar por este aviso.

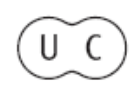






vol. 25 - número 49 - março 2016

vol. 25 - número 49 - março 2016

Fundação Eng. António de Almeida

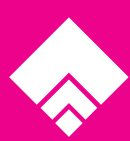




\section{MICHEL HENRY E A NOÇÃO DE ARTE MICHEL HENRY AND THE NOTION OF ART}

JOSÉ MANUEL HELENO*

Resumo: Ao iniciarmos a nossa reflexão sobre a noção de representação/abstração na obra de arte temos o intuito de mostrar a posição de Michel Henry sobre esta perspetiva. De facto, é no contexto de uma reflexão sobre a obra teórica e pictórica de Kandinsky que Michel Henry defende a arte como sendo a expressão de um sujeito, ou antes, da própria vida. A relação intima entre arte e fenomenologia, expressão do enigma da vida em si mesma, é um dos temas fundamentais da filosofia henryana.

Palavras-Chave: arte; abstração; afeto; belo; encarnação; fenomenologia; imanência; invisível; representação; sensibilidade; vida.

\begin{abstract}
Our aim is to think about representation/abstraction in the work of art, particularly de position of Michel Henry about Kandinsky. The close relation between art and phenomenology shows art as the expression of one subject, this is, life in itself. The greatest riddle of Henry's philosophy is life, precisely what is visible in art.
\end{abstract}

Keywords: art; abstraction; affection; beautiful; incarnation; phenomenology; immanence; invisible; representation; sensibility; life.
Résumé: On examine la notion de représentation/abstraction dans l'œuvre d'art, particulièrement la position de Michel Henry sur le sujet. Effectivement, c'est dans le contexte d'une réflexion sur la peinture et l'œuvre théorique de Kandinsky que Michel Henry a défendu l'art comme l'expression d'un sujet, c'est-à-dire, de la vie elle-même. La relation intime entre l'art et la phénoménologie, qui exprime l'énigme de la vie, c'est un topique fondamentale de la philosophie d'Henry, la façon de comprendre les phénomènes du monde à partir de l'auto-affection, essence de l'affectivité

Mots-clefs: art, abstraction, afection, beau, incarnation, phénoménologie, imanence, invisible, représentation, sensibilité, vie.

* Investigador no Centro de Estudos de Filosofia - Faculdade Católica de Lisboa; jmmheleno@gmail.com 
"O artista verdadeiro é um foco dinamogéneo; o artista falso ou aristotélico é um mero aparelho transformador, destinado apenas a converter a corrente contínua da sua própria sensibilidade na corrente alterna da inteligência alheia."

Álvaro de Campos, Apontamentos para uma estética não aristotélica (1925).

\section{Representação e abstração}

A "passagem" da arte figurativa à abstrata não é compreensível se não interrogarmos o que se entende por representação. Desde os primórdios do pensamento filosófico grego que a noção de representação foi entendida como mimesis, algo que permitia imitar a realidade ao criar um simulacro. Há, neste sentido, uma necessidade de repensar conjuntamente história, arte e filosofia, o que equivale a dizer que é necessário pensar a génese e a função da representação, o estatuto que assumiu na arte e a forma como foi associada à noção de verdade e adquiriu uma importância capital no pensamento filosófico. Ora, que se passou quando se começou a desacreditar e a destroçar a mimesis do papel que assumiu séculos a fio? Que alterações históricas, artísticas e filosóficas possibilitaram a passagem para uma arte, como a do século vinte, que defende a ausência de representação? Até na filosofia se abandonou a dependência endémica da noção de verdade à noção de representação? ${ }^{1}$

Mas será que conseguimos livrar-nos das noções de imitação, figuração ou representação? Platão, ao criticar a noção de mimesis, não o fez de forma descuidada, antes levou a cabo uma reflexão que apresenta várias perspetivas. Assim, se considera que a arte é uma cópia de uma cópia e deve, por isso, ser rejeitada, noutras reflexões considerou que estamos condenados a imitar qualquer coisa que não conhecemos: "imitamos uma ausência e não uma presença" ${ }^{2}$. Há até uma expressão soberba de Platão que considera a filosofia como a tragédia suprema, pois a sua função é a de imitar a vida (como também o dirá algures Michel Henry).

Se pensarmos que a representação acaba por dignificar o representado, o mundo, precisamente, compreendemos a perseverança e o sucesso da arte figurativa. É que para alguns o mundo tem uma riqueza ontológica inigualável - a ponto de apenas ele ser "belo" -, de forma que aquilo que o representa esforça-se por devolver ao espetador essa beleza suprema. E compreende-se ainda que a arte, ao ser uma forma privilegiada de relacionar o mundo e a imagem, tenta aproximar-se do primeiro e dar uma imagem fiel dele. Assim,

1 Que nos seja permitido remeter o leitor para o nosso texto "Por que não espirrar?". Em O lugar da utopia (Lisboa: Fim de Século Editores, 2000), 53-58.

2 Cf. France Farago, A arte (Porto: Porto Editora, 2002), 34. 
a arte é tanto mais verdadeira quanto mais se aproximar da realidade, do mundo, justamente. De tal forma que se torna uma aparência, mas uma bela aparência, capaz de se autodestruir, precisamente por ser uma imagem da realidade. Entendamo-nos: a verdadeira arte deve desaparecer para mostrar o representado - pois é apenas para isso que existe. ${ }^{3}$ Quando Alexandre Kojève escreve As pinturas concretas de Kandinsky, fá-lo fazendo a distinção entre belo natural e belo pintado, e salienta que devemos diferenciar o belo "na arte ou da arte" do belo "na não arte ou da não arte". Na arte clássica o pressuposto era de que a arte extraía a beleza da coisa bela e "encarnava-a" no seu estado puro. O belo tinha então um valor - mas esse valor era a encarnação do que existia na natureza e que a pintura podia extrair. ${ }^{4}$

Como veremos nas páginas que se seguem, Michel Henry defende que não devemos pensar a arte como mimesis, pois a obra de arte nada tem a ver com a noção de representação. Compreender a arte é compreender a sensibilidade do sujeito que a produz ou que dela usufrui, o que equivale a dizer que sem essa imanência ou essa doação do ser a si mesmo a arte não teria qualquer sentido. Não se trata, por conseguinte, de compreender a arte considerando o objeto que imita ou representa, mas sim de apreender radicalmente aquilo que ela mostra ao superar ou destruir o objeto.

Ora, também Kandinsky, um artista que nos ajuda a compreender a perspetiva henryana da arte, referiu, nos seus escritos, que alcançou a mestria pictórica ao chegar a esse ponto em que deixou de haver objeto, ou seja, figuração. Elogia, assim, uma pintura pura e absoluta; pintura onde a cor se libertou decididamente da tirania dos objetos e mostra aquilo que é, quer dizer, a sua criatividade ontológica (expressão nossa). Deste modo, ao querer mostrar o mistério da cor, Kandinsky celebra a vida e confessa que aquilo que se esforçou por mostrar pictoricamente foi uma velha obsessão sua: a do próprio mundo da vida, com o seu jogo de cores e os sons que ressaltam cada vez que as cores se conjugam com outras. Podemos até atrever-nos a dizer que Kandinsky quer ter sobre o mundo um olhar pessoano, de acordo com mestre Caeiro, ao ver na natureza aquilo que ela é em si mesma - e aquilo que ela é são cores e formas.

Ainda no horizonte de uma compreensão da noção de arte para Michel Henry, relembremos que Kandinsky, ao defender o espiritual na arte, acusou o materialismo de impedir a convivência com a essência da arte, a sua ver-

3 Escreve Le Clézio em $O$ êxtase material: "A arte, enquanto forma paroxística da linguagem, tem como intenção suprema a destruição da arte. Toda a arte que não tem como necessidade a ultrapassagem da sua mensagem, isto é, da sua morte, é ineficaz." Cit. in Farago, A arte, 22.

${ }^{4}$ Remetemos o leitor para a tradução castelhana do texto de Alexandre Kojève, Las pinturas concretas de Kandinsky (Madrid: Editorial Abada, 2007). 
dade ou necessidade interior. Desde o início Do Espiritual na arte (1911) faz apelo à necessidade de viver a arte e criar uma empatia entre artista $\mathrm{e}$ espetador, sendo a obra um testemunho da vida do artista, quer dizer, das suas emoções. Lastimando a indiferença como as pessoas se passeiam em museus por entre uma multiplicidade de telas com um número inesgotável de motivos, considera Kandinsky que a única arte possível é aquela que é espiritualmente sentida. $\mathrm{O}$ espetador deve vibrar; deve compreender a arte como testemunho de uma época - pois a obra de arte é a marca irrepetível de uma época histórica.

\section{Sensibilidade e arte nova}

Em "Apontamentos para uma estética não aristotélica", texto inicialmente publicado em Athena ${ }^{6}$, revista dirigida por Fernando Pessoa, Álvaro de Campos aposta na defesa de uma estética não aristotélica. Tal como há geometrias não euclidianas, também há uma estética não aristotélica, precisamente por não se basear na noção de beleza mas na de força. Escreve Álvaro de Campos: "A arte, para mim, é como toda a atividade, um indício de força, ou energia; mas, como a arte é produzida por entes vivos, sendo pois um produto da vida, as formas da força que se manifestam na arte são as formas de força que se manifestam na vida"7. E o heterónimo de Pessoa continua considerando que a força vital é dupla, ou seja, que não há vida se não existir ação e reação. Se a vitalidade de um organismo reside na intensidade da sua força de reação, tal pressupõe uma igualmente grande (intensa) força de ação. A vida é então medida pela intensidade destas forças duplas que se equilibram dinamicamente.

Posteriormente, escreve ainda A. Campos: " Ora a arte, como é feita por se sentir e para se sentir - sem o que seria ciência ou propaganda - baseia-se na sensibilidade. A sensibilidade é pois a vida da arte" 8 . Acresce que dentro da sensibilidade é que tem de haver ação e reação, o que significa que a sensibilidade tem graus de intensidade e se equilibra dinamicamente devido às forças referidas. Entendemos então a sensibilidade como um jogo entre forças (a vida), só havendo sensibilidade se existirem essas forças. Assim, nesta nova conceção estética é o particular que interessa; em vez de se atender ao geral, é este que "deve ser particularizado, o humano que se deve pessoalizar, $\mathrm{o}$ «exterior» que se deve tornar «interior»" ${ }^{9}$.

5 Kandinsky, De lo Espiritual en el Arte (Barcelona: Barral - Labor, 1983).

6 No 3 e 4. Lisboa: dez.- jan. 1924-25.

7 Fernando Pessoa, Obras em prosa. Vol. 2, (Lisboa: Europa-América, 1986, 229230). Itálicos nossos.

8 Fernando Pessoa, Obras em prosa, 230.

9 Ibid., 231. 
Por conseguinte, em vez de uma conceção tida como aristotélica, baseada na ideia de beleza, na agradabilidade e na inteligência, enfim uma arte "construída e inorgânica", a segunda conceção, a do próprio Álvaro de Campos, considera a arte baseada na ideia de força, precisamente porque se baseia na sensibilidade. Deste modo, "toda a arte parte da sensibilidade e nela realmente se baseia. Mas ao passo que o artista aristotélico subordina a sua sensibilidade à sua inteligência, para poder tornar essa sensibilidade humana e universal, ou seja, para a poder tornar acessível e agradável, e assim poder captar os outros, o artista não aristotélico subordina tudo à sua sensibilidade, converte tudo em substância de sensibilidade, para assim, tornando a sua sensibilidade abstrata como a inteligência (sem deixar de ser sensibilidade), emissora como a vontade (sem que por isso seja vontade), se tornar um foco emissor abstrato sensivel que force os outros, queiram eles ou não, a sentir o que ele sentiu $(\ldots)^{10}$.

O que nos parece extraordinário neste apontamento estético é a sua consonância com as teses de Michel Henry. A ênfase dada à sensibilidade; a ideia de que a arte deve ser entendida a partir da noção de força (de intensidade) e a forma como o «exterior» se deve tornar «interior», são considerações que podemos encontrar nas reflexões de Michel Henry. E não deixam de ser esclarecedoras as últimas palavras que o filósofo escreveu sobre Kandinsky, e que teremos oportunidade de comentar, quando fala das "forças que dormitam em nós e esperam há milénios"; das "forças que explodem na violência e resplandecência das cores"; das "forças do cosmos", enfim, tudo aquilo que permite compreender - como diz a última frase do livro - que a "arte é a ressurreição da vida eterna".

Como procuraremos referir nas páginas que se seguem, nas primeiras décadas do século vinte despontava uma nova perspetiva sobre o que deveria entender-se por arte, em particular sobre pintura, que artistas como Kandinsky, Klee ou Matisse, por exemplo, teorizaram nos seus escritos. Uma referência sucinta a Matisse permite-nos compreender a sua preocupação com as sensações. Para ele o fundamental era dar estabilidade às sensações mediante composições estáveis, mais do que interessar-se por sensações fugidias, como era o intuito dos impressionistas. Assim, em resposta a Clara MacChesney, em 1913, que o interroga sobre qual era ao certo a sua teoria sobre a arte, afirma: "Pois bem, considere aquela mesa, por exemplo. Não pinto literalmente aquela mesa, mas a emoção que ela produz em mim" 11 .

O abandono da cor local, a ampla liberdade no uso da cor e a preocupação com o "conjunto", justifica-se pela ideia de que a pintura não tem de ser escrava da natureza. Com efeito, "a tendência dominante da cor deve ser o

10 Ibid., 233.

11 Henry Matisse, Escritos e reflexões sobre arte (Lisboa, Editora Ulisseia, s/d.), 38. 
de servir o melhor possível a expressão. Aplico os meus tons sem preconceitos" 12. E mais à frente: "Quanto a mim, procuro apenas utilizar cores que exprimem a minha sensação. Há uma proporção necessária dos tons que pode levar-me a modificar a forma de uma figura ou a transformar a composição. Enquanto não a obtiver em todas as partes, procuro-a e continuo o trabalho"13.

Contudo, também filósofos como Ortega y Gasset desenvolveram uma reflexão sobre arte que gostaríamos de recordar. Escreve o filósofo espanhol em $A$ desumanização da arte que "toda a arte jovem é impopular, e não por acaso e acidente, mas em virtude do seu destino essencial"14. E continua na página seguinte: "Não se trata do facto de a maioria do público não gostar da obra jovem, que agrada à minoria. $\mathrm{O}$ que acontece é que a maioria, a massa, não a entende".

O intuito de Ortega ao defender a desumanização da arte - num ensaio que foi escrito, note-se, em 1925, no mesmo ano de "Apontamentos para uma estética não aristotélica" - é o de mostrar que a "nova" arte, a do século vinte, rompe com a tradição humanista anterior e revela-se, por isso, difícil de entender. Ortega insiste nessa compreensão da arte como uma forma de apreciar aquilo que nela existe de inovador. Ora, tal remete invariavelmente para questões sociológicas, em particular o facto de à maioria não agradar nada que se afaste da figuração ou representação das coisas. O que interessa à maioria é aquilo que se pode ver para além da janela - da tela - e não o vidro propriamente dito..$^{15}$

Deste modo, e de acordo com a metáfora de Ortega, a nova arte insiste em chamar a atenção para os meios de representação, pois é nisso que se revela arte. É assim que a arte nova triunfa sobre o humano, o que equivale a dizer que "a «realidade» assedia constantemente o artista visando impedir a sua evasão"16. Ortega mostra como é difícil para a nova arte evadir-se da realidade, ou seja, não se limitar a copiar o que se vê antes insistindo na capacidade de incidir sobre os meios de representação - como se a arte fosse mais

12 Henry Matisse, Escritos e reflexões sobre arte, 39.

13 Ibid., 40.

14 José Ortega y Gasset, A desumanização da arte e outros ensaios de estética (Coimbra: Almedina, 2003), 40.

15 O quadro como uma janela aberta para o mundo é uma ideia de Léon-Battista Alberti (séc. XV). Teórico e artista (arquiteto) é da sua autoria um Tratado da pintura e Da arquitetura. É no Tratado da pintura que escreve: "Aqui, deixando de lado tudo o resto, direi apenas o que faço quando pinto. Em primeiro lugar, onde devo pintar. Traço um quadrilátero de ângulos retos do tamanho que pretendo, o qual considero ser uma janela aberta através da qual olho o que aqui vai ser pintado." Cit. in Jean Luc Chalumeau, As teorias da arte (Lisboa: Instituto Piaget, s/d), 33-34.

16 José Ortega y Gasset, A desumanização da arte e outros ensaios de estética, 53. 
desconfiada e se desumanizasse ao pensar-se como forma de representação do mundo. É esse o desafio na música, literatura, pintura e escultura. Mais do que a realidade, interessa ao artista as ideias que se têm sobre a realidade. "O expressionismo, o cubismo, etc., foram em diversa medida tentativas de verificar essa resolução na direção radical da arte. Passou-se de pintar as coisas a pintar as ideias: o artista cegou-se perante o mundo exterior e virou a pupila para as paisagens interiores e subjetivas" ${ }^{17}$.

Tanto a reflexão de Álvaro de Campos como a de Ortega y Gasset - ambas datadas de 1925 - parecem-nos importantes para compreender a noção de arte para Michel Henry. A noção de sensibilidade, a ideia de força e a crítica à noção de representação/ figuração são vértices essenciais para podermos aceder à perspetiva do filósofo francês. É neste contexto que podemos perguntar: será a arte essencialmente fenomenológica?

Em diversos textos, Michel Henry insistiu na subordinação da ontologia à fenomenologia, ou seja, o ser é prioritariamente um aparecer. A tarefa fenomenológica assenta no aparecer puro, o mostrar ou manifestar do ente tomando em consideração o seu modo de aparecer mais do que o aparecer propriamente dito. Os diferentes modos de aparecer do ente - em presença, imaginação, memória ... - indicam assim o intuito fenomenológico. Ora, não terá a arte a incumbência fenomenológica de nos dar a ver esse aparecer do ente? Um quadro, uma escultura, um poema, possibilitam a eclosão desse aparecer, quer seja dado como "real" quer como "imaginário".

Para além desta capacidade fenomenológica, a arte também assinala o mais insigne dos empreendimentos: a de nos dar a ver o invisivel, oximoro que reúne o visível àquilo que, em si mesmo, não o é, pois trata-se dessa doação absoluta e fundamental que é a própria vida. Escreve Michel Henry:

17 Ibid., 63. Vale a pena relembrar, a este respeito, o suprematismo de Malevich. De facto, o célebre Quadrado negro (1914-15), não representa nada, mas desarma o espetador por isso, obrigando-o a tentar criar uma interpretação e a analisar o preto, o branco e o quadrado de outra forma. Até as histórias que se contam sobre o que é efetivamente o quadrado reforçam esta necessidade interpretativa. Expliquemo-nos: sabe-se que o quadrado negro, do quadro homónimo, é tinta sobre qualquer coisa que Malevitch tinha inicialmente pintado. Mas cansado e desiludido com a pintura e a sua ânsia figurativa, o pintor russo tratou de apresentar um quadro que dissesse tudo o que havia a dizer: que há apenas, numa tela pintada de branco, um quadrado preto ligeiramente inclinado, como se este fosse a ausência de cor, o vazio, portanto. Em Quadrado negro há o todo (o branco) e o nada (o preto) e estamos, por isso, condenados a interpretar aquilo que parece não o admitir, tal a pobreza de elementos que o constituem. 
"Existe assim uma autodoação fundamental da qual a realidade fenomenológica é um pathos, uma afetividade que eu chamo transcendental - como se chamou transcendental à consciência que torna possível o mundo e os objetos. Esta afetividade é um pathos que é a Vida e a sua carne fenomenológica é feita de uma espécie de oscilação entre o sofrimento e a alegria"18.

Deste modo, é no contexto da fenomenologia - e em diálogo com a sua conceção clássica, vinda de Husserl e de Heidegger -, que Michel Henry vê a fenomenologia da vida como uma revelação. Tal significa que a vida se revela a ela própria no seu aparecer. Por conseguinte, "a revelação da vida e aquilo que se revela nela são um só" ${ }^{19}$. Enquanto o aparecer, no sentido da fenomenologia clássica, era um aparecer de algo exterior - um "hors de soi" - a revelação da vida é um revelar-se ela própria nela própria, ou seja, uma revelação que só pode ser autorrevelação.

Para mostrar esta imanência absoluta (pois a relação "da vida ao vivente é uma relação de imanência absoluta"), Michel Henry fala tanto em invisibilidade como em encarnação - palavras que parecem excluir-se quando são, na verdade, essenciais para explicar o intuito do filósofo. Com efeito, "na "ausência de todo o afastamento interior do sofrimento, é a possibilidade de dirigir sobre ele um olhar que é excluída. Nunca ninguém viu o seu sofrimento, a sua angústia, a sua alegria. $\mathrm{O}$ sofrimento, como toda a modalidade da vida, é invisível" 20 . Esta invisibilidade assinala a imanência absoluta, a autorrevelação, enfim o facto de a vida ser de uma passividade radical que não cessa de s'éprouver soi-même. É esta capacidade de a vida se experimentar a ela própria que a torna invisível, se bem que encarnada num corpo. Daí que aquilo que a vida de cada um é consiste em afetos que se fazem carne e se tornam, por isso, numa vida. Michel Henry insiste que a vida está marcada por uma passividade radical a respeito de si própria. Escreve: "Da arqui-passividade da Vida absoluta resulta ainda o carácter mais singular da condição humana que é a de ser uma existência encarnada" 21 .

Qual a importância destas considerações para a noção de arte? Se lhe compete revelar a vida, deve então chamar a atenção para aquilo que é e sempre permanecerá, assinalando, de várias maneiras, a singularidade da condição humana e a forma como esta, na sua finitude, se vai encarnando.

18 Michel Henry, Auto-donation. Entretiens et conferences (Paris: Beauchesne, 2004), 20.

19 Michel Henry, Auto-donation. Entretiens et conferences, 33.

20 Ibid..

21 Ibid., 40. 


\section{Ver o invisível}

A obra Ver o invisivel. Sobre Kandinsky tem a sua primeira edição em 1988. Acompanhada de reproduções de alguns quadros de Kandinsky, tal não sucede com a publicação das edições PUF em $2005^{22}$ (apesar de continuarem, no corpo do texto as referências às obras pictóricas de Kandinsky). Em Ver o invisivel, Michel Henry insiste na inovação radical protagonizada por Kandinsky, ou seja, ela é radical porque é não figurativa, o que a torna verdadeiramente inovadora e a diferencia de artistas como Picasso, Mondrian, Malevitch ou Klee, por exemplo. Ora, compreender a obra de Kandinsky é compreender a possibilidade de toda a pintura. Esta afirmação, aparentemente dogmática, é explicitada no seguimento da reflexão de Michel Henry, embora permaneça efetivamente um desafio para qualquer leitor a ideia de que podemos compreender toda a pintura a partir da pintura abstrata.

Outra afirmação ousada nas páginas iniciais de Ver o invisivel é a que considera que Platão, Aristóteles, Kant, Schelling, Hegel ou Heidegger - cujas reflexões estéticas marcaram a nossa compreensão da arte - "não perceberam nada de pintura"23. Parece, assim, necessário pensar o intuito radicalmente inovador de Kandinsky e compreender a pintura e consequentemente a própria arte.

Michel Henry inicia a sua reflexão começando por referir a distinção entre exterior e interior na obra teórica de Kandinsky Assim, o exterior e o interior são "dois modos de aparecer", e é a perspetiva que se tem deles que delimita a pintura tradicional da pintura abstrata. De facto, para Michel Henry, leitor, espetador e intérprete de Kandinsky, se a conceção clássica da pintura via no mundo um exterior que podia ser apreendido por meio de técnicas como a cor e a forma, trata-se agora de defender que "não há exterior", ou seja, que aquilo que se vê no quadro é uma forma, subjetiva, de expressar a própria vida. Mas se não há exterior também não há interior, pelo menos se este for entendido como o reverso do outro. Como diz Michel Henry: "Não há «mundo interior». O interior não é a réplica voltada para dentro de um primeiro exterior (Dehors). No interior, não há nenhum pôr à distância, nenhum pôr em mundo - nada de exterior porque não há nele nenhuma exterioridade" ${ }^{24}$. Ora, se o exterior é o visível e o interior o invisível, é necessário entender estas expressões de outro modo, de forma a compreender que o interior é a vida, a afetividade, e que é este "invisível" que se pinta.

22 Todas as nossas citações remetem para esta edição: Voir l'invisible. Sur Kandinsky

(Paris: Quadrige/Puf, 2005).

${ }^{23}$ Michel Henry, Voir l'invisible, 11.

24 Ibid., 18. 
Aparentemente parece descabida a ideia de que o pintor não pinta as coisas, o exterior. Assim, o que interessa a Michel Henry é a obra em si mesma, quer dizer, não tanto a tela, a madeira, o vidro, mas fundamentalmente a obra enquanto tal, o que se vê no quadro. Na pintura abstrata realçam-se pontos, linhas, cores e formas, justamente a matéria da pintura, aquilo que faz da pintura uma pintura. Poderíamos dizer que toda a pintura figurativa parte desses elementos, embora haja a intenção de servir o real. Para Kandinsky e Michel Henry todos esses elementos são a própria pintura, a sua essência. Como escreve Michel Henry, enunciando dois "pensamentos loucos": "10 O conteúdo da pintura, de toda a pintura, é o Interior, a vida em si mesma invisível e que não pode deixar de o ser, que permanece para sempre na sua Noite; $2^{\circ}$ Os meios pelos quais se trata de exprimir este conteúdo invisível as formas e as cores - são eles mesmos invisíveis, na sua realidade original e, em todo o caso, a mais própria" ${ }^{25}$. A equação kandinskiana pode então ser compreendida: Interior $=$ interioridade $=$ invisível $=$ vida $=$ pathos $=$ abstrato .

Mas que podemos entender por abstração? Michel Henry considera que a abstração é a capacidade de isolar determinados aspetos do real. Este é, pelo menos, um dos sentidos que atribui ao termo. Contudo, se relermos as páginas iniciais de Ver o invisivel, compreenderemos que o autor flexibiliza o termo, pois tanto considera que só o mundo é concreto - porque o mundo é o todo e só o todo tem essa característica - como insiste que a pintura que é tida como abstrata não o é tal como essa expressão é atribuída à pintura de Kandinsky. Com efeito, o cubismo, por exemplo, é ainda figurativo - "pertence ao projeto figurativo" 26 - e deve compreender -se "como uma da suas modalidades", acrescenta o autor. Assim, ao longo da sua reflexão - e nem sempre de uma forma clara e distinta, para nos servirmos das noções cartesianas - Michel Henry diferencia vários graus de abstração. Se no início dá a entender que toda a arte é abstrata - até a arte figurativa - pois isola um aspeto do real, considera-se posteriormente que até o cubismo ou o suprematismo de Malevitch não o são. O cubismo, como referimos, não é ainda suficientemente abstrato - o que parece contrariar as primeiras reflexões sobre esta noção.

Escreve o autor: "A pura abstração de Mondrian e Malevitch é precisamente a abstração da geometria, uma abstração que provém do mundo e lhe pede de empréstimo a sua própria natureza ao mesmo tempo que pretende formular o essencial. O que é o mundo, com efeito, senão «qualquer coisa que tem comprimento, largura e profundidade?»" 27 . Trata-se, portanto de uma abstração vinda da geometria, algo que se pede emprestado ao mundo e não é, por isso, radicalmente abstrata.
25 Ibid., 24
26 Ibid., 28.
27 Ibid., 29. 
O que Michel Henry entende por abstração kandinskiana não é uma "remodelação da figuração percetiva", mas a vida invisivel. De facto, "a vida é o conteúdo da pintura". E o autor acrescenta: " «Abstrato» não designa mais aqui aquilo que provém do mundo no termo de um processo de simplificação ou de complicação, no termo de uma história que seria a da pintura moderna - mas isso que era antes dele e não tinha necessidade dele para ser: a vida que se abraça na noite da subjetividade radical onde não há nem luz nem mundo" 28 . Daí que possa então escrever: "O conhecimento ao qual a arte nos abre é de uma natureza totalmente diferente: é um conhecimento sem objeto. O seu meio ontológico é a vida - a vida que se abraça a ela mesma inteiramente sem jamais se separar de si, sem se pôr em face de si à maneira de um ob-jeto" ${ }^{29}$. Aquilo que Kandinsky pretende pintar é estranho ao mundo utilitário. Mas como pode então pintar a própria vida? Como é possível?

Ao querer pintar a "vida invisível", Kandinsky dá-lhe uma forma ou matéria. Michel Henry insiste nestes pontos: o conteúdo da pintura é a vida invisível enquanto a forma é a materialização da vida através dos seus elementos como o ponto, a linha e o plano. Escreve o autor: "O génio de Kandinsky é o de não apenas ter levado esta capacidade de pintar o invisível - as nossas pulsões, os nossos afetos, a nossa força - a um grau nunca alcançado, mas ainda ter produzido a explicação desta capacidade extraordinária" 30 .

À semelhança de Heidegger, Michel Henry mostra à sua maneira que a pintura é uma "contra-perceção". Significa isto que os objetos não são vistos de uma forma prático-utilitária na tela, pois as formas e as cores não querem figurar os objetos, representá-los, antes valem por si ao serem percebidos na sua pureza. Se a forma e a cor costumam significar em função daquilo que representam, pois toda a perceção é prático-utilitária, o mérito de Kandinsky, tanto na qualidade de artista como na de teórico da arte, é o de ter defendido que a pintura deve mostrar a forma e a cor libertas dos objetos e sem a tendência prático-utilitária como são encaradas. A pintura deve mostrar a cor e a forma na sua pureza, convidando o espetador/observador a compreendê-las por elas próprias ao desvinculá-las dos objetos. A insistência de Kandinsky em destruir ou destituir o objeto da sua importância na história da pintura prende-se com esta necessidade de compreender a cor e a forma em si mesmas. Somos, por isso, conduzidos à abstração pela ressonância, como se o fundamental fosse a necessidade de experimentar / sentir o pathos da cor, a forma como essa cor se manifesta ${ }^{31}$.
28 Ibid., 33.
29 Ibid., 37.
30 Ibid., 50.
31 Ibid., 226. 


\section{Conhecimento, arte e fenomenologia da vida}

O conhecimento verdadeiro é o conhecimento objetivo? A pergunta de Michel Henry em Ver o Invisivel tem como pressuposto a revolução artística protagonizada por Kandinsky. Já sabemos que aquilo que a obra de arte revela é a possibilidade de existir "um conhecimento sem objeto" 32 , quer dizer, "o seu meio ontológico é a vida". Em vez de um conhecimento rigoroso, científico; um conhecimento que se esmera em "ver o objeto em todas as suas especificidades e minudências", Michel Henry valoriza a inovação de Kandinsky na medida em que mostra a possibilidade de a arte visar a própria vida, precisamente o que é invisível e não objetivo.

Assim, o que escapa à ciência é a vida. Nos textos coligidos no terceiro volume de Fenomenologia da vida - intitulado Da arte e da política - temos uma sinopse das reflexões que Michel Henry dedicou à estética, em particular a Kandinsky. Com efeito, para além de Kandinsky responder pictoricamente ao intuito galilaico, nomeadamente ao ensejo de Galileu de se tornar "rigoroso", expulsando tudo o que dissesse respeito à subjetividade - como cores, sabores, etc. -, foi também Kandinsky que antecipou o projeto do próprio Michel Henry, a saber, o da necessidade de rever a metafísica ocidental e a sua obsessão pela "exterioridade". Se o importante para Michel Henry é a vida e o mistério da sua autoafeção, ou melhor, o de uma afetividade que se afeta a si mesma, compreende-se o seu afastamento em relação a tudo aquilo que procura uma racionalidade do real e a compreensão concomitante do "exterior".

Deste modo, a significação da obra de arte é a de exprimir a "alma", a de cada um e a do universo ${ }^{33}$, devendo esta afirmação ser compreendida no sentido da vida. Quer dizer a arte pinta a vida enquanto "potência de crescimento" capaz de se experimentar a ela própria ${ }^{34}$. A inflexão de Michel Henry é a de se apropriar das noções kandinskianas de ressonância, necessidade interior, interioridade e tantas outras, mostrando que estas noções retratam aquilo que, no plano filosófico e romanesco, é defendido pelo autor de Ver $O$ invisível. Na verdade, quando Kandinsky afirma que "não pinta estados de alma", esta expressão só é estranha e contraditória para quem não entende que a vida que se quer pintar não são meros "estados" mas poderes que se intensificam. É esta, pelo menos, a leitura de Michel Henry.

Mas será que foi isso que Kandinsky quis efetivamente dizer? E será legítimo dar-lhe esse protagonismo no contexto da pintura moderna? Afinal, a

32 Ibid., 37.

33 Cf., o ensaio "Kandinsky et la signification de l'oeuvre d'art", em De l'art et du politique. Phénoménologie de la vie. Tome III (Paris: PUF, 2004).

34 Henry, "Kandinsky et la signification de l'oeuvre d'art", 217-218. 
questão da arte abstrata e a sua luta contra o objetivismo e a figuração não nos podem fazer esquecer que a cor e a forma pictóricas também podem mostrar o seu valor e importância num quadro figurativo. É neste aspeto que poderíamos afirmar que ver a cor e a forma por elas próprias, o seu poder vital, não significa necessariamente desligá-las do mundo e compô-las de maneira sui generis. Outra objeção, tantos aos argumentos de Michel Henry como aos do próprio Kandinsky, seria a de mostrar que, mesmo onde há figuração, a cor e a forma também podem assumir a sua rebeldia e a sua "irrealidade".

No entanto, não é esta a maneira de pensar dos autores referidos. Relembremos que se Michel Henry, nas páginas terminais de Ver o Invisivel, fala das pinturas religiosas e considera que "elas escapam à esfera da figuração", é porque é fundamental para a sua compreensão a composição e a ressonância das cores. Seria, aliás, absurdo falar de uma realidade que pretendessem representar. O que o filósofo valoriza na revolução protagonizada por Kandinsky é o facto de o quadro poder ter uma forma pura, liberta do objeto, de tal modo que a pintura se torna numa "contra-perceção" 35 . É a este propósito que se enaltece não apenas a cor e a forma como também o ponto, a linha e o plano. "Assim, o mundo das linhas, escreve Kandinsky, inclui todas as sonoridades possíveis, do lirismo frio ao drama ardente." Esta citação de Ponto, linha e plano em Ver o Invisivel ${ }^{36}$, indica as "possibilidades expressivas da linha”. Mas não só. Michel Henry mostra como se deve levar a sério as reflexões de Kandinsky sobre o ponto, a linha e o plano. Trata-se, na verdade, de chamar a atenção para as potencialidades destes elementos e a importância que possuem no mundo e na pintura. Trata-se, assim, de um olhar novo; uma forma diferente de considerar o ponto, o dinamismo da linha e a importância do plano original. A linha, por exemplo, perde a sua força se acaso é vista na pintura figurativa como um mero elemento exterior, quer dizer, um traço que é compreendido como um contorno de uma figura que interessa reproduzir. A linha torna-se, neste contexto, um elemento desnecessário, como um auxiliar para a suposta compreensão do mundo. Ora, na pintura de Kandinsky a linha liberta-se destes constrangimentos e começa a ser vista nela própria, na sua sonoridade, interioridade, enfim, na sua vida. Michel Henry insiste nesta necessidade de ver de outro modo os elementos, destacando esta temática tanto na reflexão de Kandinsky sobre a pintura como na revolução pictórica que protagonizou.

Em Ver o invisivel pode também ler-se: "Na relação da vida à obra de arte, não há nenhum olhar suscetível de conferir um sentido, um valor ao objeto, porque não há nem olhar, nem sentido, nem objeto, porque a relação da vida à cor, por exemplo, é a subjetividade desta, ou seja, a própria vida."

35 Cf., Michel Henry, Voir l'invisible, 53.

36 Em Michel Henry, Voir l'invisible, 93. 
Esta forma radical de entender a arte pictórica de Kandinsky mostra como, a este respeito e no contexto da arte abstrata em geral, os discursos correm o risco de se tornarem supérfluos. Mais do que procurar uma referência ou sentido, importa o encontro entre o que se vê e o que se sente.

Se é o mistério da vida que se pretende apreender sem jamais o conseguirmos, qual o poder da arte a este respeito? Como pode a arte dar conta da fenomenologia da vida? Se a "sensibilidade é o ek-stase do ser"; se ela é a "abertura deste mundo, a transcendência em e pela qual nasce o primeiro Exterior (Dehors)" "37, a arte é essa forma de conhecimento sensível que assume a vida como a sua razão de ser. Ora, ao refletirmos sobre a pintura e em particular sobre Kandinsky, a pergunta que surge é a de saber porque se sentiu Michel Henry atraído pelo autor de $O$ espiritual na arte? Com efeito, a resposta surge nas primeiras páginas do livro que lhe dedicou ${ }^{38}$ : a singularidade do pintor russo e a natureza dos seus escritos são aspetos fundamentais para a compreensão da arte.

Seria interessante, aliás, analisar a forma como Michel Henry interpreta Kandinsky e lê não só Maine de Biran como Marx e os evangelhos sinóticos. E não seria difícil detetar a mesma metodologia, a mesma necessidade de pensar o visível e o invisível, embora este último tanto possa indicar a espiritualidade da arte como o "segredo" de cada vida humana, o qual, numa perspetiva religiosa, permite a comunicação com o divino ${ }^{39}$. Neste sentido, as palavras de Cristo, se têm uma dimensão humana porque se compreendem na interlocução quotidiana, são também palavras que revelam o Filho de Deus. É por isso que o paradoxo, longe de ser um episódio fugaz na estrutura dos discursos do Filho de Deus, são antes a forma como este tem de apelar à sua origem divina e à necessidade de, sem complacências, mostrar a sua Verdade.

Quando os evangelhos falam reiteradamente da necessidade de amar os que nos odeiam; de dar graças aos pobres e infelizes; de incentivar os que quebram os laços familiares para que outro Pai possa ser recebido, percebe-se que este gosto pelo paradoxo faz do cristianismo uma verdade sui generis. É isto, pelo menos, o que pensa Michel Henry. E é interessante que um filósofo que tanta importância deu ao corpo e à vida na sua imanência,

37 Cf. Michel Henry, De l'art et du politique. Phénoménologie de la vie. Tome III, 207.

38 Michel Henry, Voir l'invisible. Sur Kandinsky.

39 Escreve Michel Henry em Palavras de Cristo (Lisboa: Edições Colibri, 2003, 35) que o segredo não tem apenas a ver com a nossa condição humana. De facto, se o segredo é o invisível no nosso trato com os outros, é preciso pensar que é atravessado pelo olhar de Deus. "Mas no invisível, este segredo, este eu misterioso e impenetrável é atravessado por um outro olhar que o atinge no coração, aí, verdadeiramente, onde está o segredo. E este olhar é nada mais nada menos que o olhar de Deus". 
absurdamente presente numa inocência sem nome, ser também o filósofo do invisível, quer dizer, da arte e da necessidade de prestar atenção à transcendência divina. Paradoxalmente, o corpo torna-se o lugar do invisível - e é por isso que Michel Henry tanto homenageia a vida, isso que, por ser o mais próximo, por ser irremediavelmente o mais próximo, pois está aqui e sempre - é também o mais longínquo.

Em La barbárie ${ }^{40}$, designadamente no prefácio que escreve para a edição de 2000, Michel Henry critica a afirmação que "o homem não é diferente das coisas" - afirmação que foi defendida pela tradição galilaica ao apostar na naturalização do conhecimento e na sua objetividade unilateral. Ora, esta crítica mostrava o desencanto do filósofo pelo rumo que o saber tinha seguido, o mesmo que exacerbava a perspetiva geométrica e matemática que Galileu protagonizou em desfavor do mundo da vida. Sabemos que o próprio Husserl, na Crise das ciências europeias e a fenomenologia transcendental, já tinha chamado a atenção para esta questão ao lamentar que a subjetividade tivesse de ser recalcada ou anulada em prol do único saber que se considerava digno desse nome: o científico ${ }^{41}$. A obra de arte, ao celebrar o mundo da vida, esquiva-se a essa pretensa objetividade que parecia exclusiva de um saber rigoroso e verdadeiro. Se para Michel Henry "nunca ninguém viu a vida e jamais a verá" 42 , é porque a vida é de uma imanência radical que a arte é capaz de pressentir.

A barbárie, essa crise em que a humanidade se encontra e a longa noite que a carateriza, tem as suas origens na maneira de encarar o saber científico e de desenvolver ideais concomitantes na compreensão da realidade, esquecendo-se aquilo que está antes de qualquer conhecimento possível: a própria vida. Neste sentido, não se pode compreender a cultura se a não entendermos como "uma ação da vida sobre ela própria", autotransformação que nada tem a ver com a ciência, pois precede qualquer forma de conhecimento que se pretenda apresentar como objetivo. A insistência na vida, quer dizer, na sensibilidade, nesse modo de ser radicalmente subjetivo que precede qualquer conhecimento, está também presente nas reflexões cartesianas pois, de acordo com Michel Henry, é preciso reinterpretar Descartes

40 Michel Henry, La barbárie (Paris: Quadrige/Puf, 2008).

41 No $\S 2$ de A Crise das ciências europeias e a fenomenologia transcendental. Uma introdução à filosofia fenomenológica (Lisboa: Centro de Filosofia da Universidade de Lisboa - Phainomenon, 2008), Husserl escreve o seguinte: “A exclusividade com que, na segunda metade do século XIX, toda a mundivivência do homem moderno se deixou determinar pelas ciências positivas, e cegar pela prosperity a elas devida, significou um virar costas indiferente às questões que são as decisivas para uma humanidade genuína. Meras ciências de factos fazem meros homens de factos."

42 Michel Henry, Phénoménologie de la vie. Tome III. De l'art et du politique, 192. 
como o pensador que estabeleceu de forma sólida o primado desse sentir-se associado ao cogito.

De facto, Descartes, de acordo com Michel Henry, foi o filósofo que ao duvidar do que via, afirmou com inabalável certeza que se sentia a si próprio no exercício do pensar. É este pensar-se como forma de sentir-se pensamento - independentemente das dúvidas sobre o que é visado pelo pensamento - que mostra o notável contributo de Descartes para a história da filosofia. Aliás, Maine de Biran, lido por Michel Henry, censurou a perspetiva cartesiana da alma como substância em vez de ver nela a subjetividade absoluta. Deste modo, o próprio Descartes não viu todo o alcance da sua descoberta: $o$ ser do ego afirmado na sua imanência radical ${ }^{43}$.

Ao escrever provocatoriamente que "o homem não é essencialmente um ser histórico" 44 , Michel Henry quer pôr em relevo aquilo que há de profundamente ontológico no ser humano. De facto, já nos anos quarenta do século passado, quando Henry faz uma leitura atenta da filosofia biraniana, é o homem enquanto sujeito que lhe chama a atenção - pretexto para elogiar Maine de Biran por ter sido "o primeiro filósofo" e o "único" 45 que compreendeu a necessidade de definir originariamente o nosso corpo como "corpo subjetivo". Mais do que um corpo biológico, animal e até humano, o corpo visto na sua subjetividade radical é uma herança que Michel Henry recebe de Maine de Biran. Daí que a verdadeira "metafísica seja uma psicologia" e que "a subjetividade seja essa "esfera da imanência absoluta". De tal modo que as categorias são deduzidas no interior de uma ontologia da subjetividade, pois só partindo dessa redução fenomenológica se compreende a forma como as noções de causa ou de força, por exemplo, se aplicam aos seres transcendentes.

Por conseguinte, o mistério é este sentir-se a si mesmo enquanto vivente. Quando Michel Henry exemplifica com o estudante de biologia ocupado a ler uma obra sobre o código genético ${ }^{46}$ fá-lo no intuito de mostrar que o fundamental é compreender aquilo que o estudante faz efetivamente com os olhos e as mãos, a forma como se sente e o saber que daí resulta. Para o filósofo "não é o saber científico que lhe permite (ao estudante) adquirir o saber científico contido no livro" 47 . De facto, é o saber feito corpo, a subjetividade radical, que importa, como se a ciência nada mais fosse do que uma abstração.

No entanto, poderia considerar-se que Michel Henry estava equivocado, pelo menos no sentido em que poderia haver conhecimento científico acerca

43 Michel Henry, Philosophie et phénoménologie du corps (Paris:PUF, 2006), 60-61.

44 Ibid., 6 (em nota de rodapé).

45 Ibid., 12.

46 Michel Henry, La barbárie, 24.

47 Ibid., 25. 
desse movimento das mãos e dos olhos, desse modo de estar do estudante quando se levanta para beber um café ou pega no livro. É nesta perspetiva que parece não haver forma de ser que escape ao conhecimento, e que até o mundo da vida, com toda a sua subjetividade, se presta a ser racionalizado e a ser compreendido de uma forma que se pretende científica. Ora, é na sequência desta nossa observação que pode surgir outra, mais profunda: a de que Michel Henry criticou o conhecimento científico a partir do paradigma galilaico quando, nos dias que correm, há conhecimentos científicos que se baseiam noutros paradigmas. Quem lê La barbarie fica com a impressão de que a ciência só pode ser galilaica, quando apareceram outros paradigmas da ciência sem que isso arruinasse o empreendimento científico, antes contribuísse para o seu aperfeiçoamento. O mundo da subjetividade radical, longe de se excluir ontologicamente desta compreensão científica, acaba por permitir o acesso ao seu território, justamente devido a flexibilidade dos paradigmas científicos que referimos.

Atentemos, no entanto, que a ideia fundamental do filósofo é a de considerar que a "ciência faz abstração dos predicados sensíveis". Para Michel Henry aquilo que a vida é não pode ser conceitualizável em qualquer forma de conhecimento. Deste modo, "no seu saber próprio, ao contrário (do saber da consciência e das ciências) a vida não revela nada de outro, nenhuma alteridade, nenhuma objetividade, nada que seja diferente dela, nada que lhe seja estranho" ${ }^{48}$. Aquilo que há na vida só ela mesma o sabe, ou seja, qualquer conhecimento, seja ou não científico, não apreende esse mundo da subjetividade radical que precede qualquer outro e não se deixa apreender por nenhuma forma de conhecimento. Ora, se a cultura é a vida na sua autotransformação, então a ciência não tem relação com ela, justamente porque não tem relação com a vida.

Mas não poderá a vida fazer uma ideia dela própria? O que é a vida para o vivente? No anseio de mostrar a prioridade transcendental deste vivente no assumir afetivo da vida que se sente, não cairá Michel Henry numa espécie de ceticismo radical? Ao dar tanto à vida e tão pouco à ciência, como compreender esta discrepância?

Se a vida se torna a principal vítima da barbárie, é porque a suposta "objetividade" do conhecimento científico e o seu pretenso rigor, para além do predomínio da técnica, significa efetivamente um afastamento da vida. É por isso que o progresso é o sintoma desse afastamento, pois nele se promove a técnica, entendida aqui como aquilo que é celebrado pelo capitalismo e por esse valor de troca todo-poderoso que o legitima. Se a vida tem uma praxis específica, uma forma do corpo se apropriar - de ser corpoapropriação

48 Michel Henry, La barbárie, 30. 
$\left(\right.$ corpspropriation $\left.^{49}\right)$ - é isso que faz da própria vida uma prática e, por isso, uma necessária fabricação e utilização de instrumentos que permitam o exercício da vida enquanto tal. Ora, com a subordinação do valor de uso ao valor de troca; com o exacerbar do consumo, não é apenas a "economia" que se altera, é também o mundo da vida que se vai esquecendo em prol da riqueza, da "técnica", enfim, da barbárie.

Deste modo, se Michel Henry reprova a ciência enquanto forma de conhecimento que se pretende objetivo e único, apoiado no desenvolvimento técnico, é porque o seu programa fenomenológico significa um desejo de se manter junto à vida, aí mesmo onde ela, a todo o momento, mostra a essência de cada um de nós. Resta saber se a reprovação desta forma de conhecimento não endeusará uma situação fenomenológica que, embora real, só pode ter em si traços de pobreza e de humildade óbvios. Significa isto que nada temos a dizer da vida se não vivê-la; que nada temos a esclarecer de uma situação de uma passibilidade extrema e de uma subjetividade radical senão senti-la - o que anula qualquer construção filosófica e qualquer tipo de conhecimento, e não apenas o científico.

É esta penúria do conhecimento, ou antes, a sua anulação, que merece a nossa incredibilidade. Sentimo-nos incrédulos porque sobre a vida apenas há uma atitude possível: vivê-la! Se "pensar incomoda como andar à chuva" - de acordo com Alberto Caeiro, então qualquer pensamento será uma forma de incomodar ou perturbar aquilo que tem valor por si mesmo. Se Michel Henry aprova efetivamente estas ideias, o que se torna mais problemático é a possibilidade de construir uma "fenomenologia da vida", ou seja, a posição radical e primordial do filósofo acaba por inviabilizar, justamente por ser radical, a construção de qualquer fenomenologia. Assim, e estranhamente, é a própria filosofia que se destrói a si mesma - um pouco como se o esclarecimento da questão significasse o desaparecimento da questão enquanto tal. Inesperadamente, seria Wittgenstein que encontraríamos no empreendimento henryano - encontro inesperado e provavelmente recusado pelo pensador francês.

Contudo, de acordo com Michel Henry, a vida transcendental ocorre no anonimato, o que mostra a passividade fundamental do vivente. Se a vida é um fluxo - como o tempo - a arte seria uma tentativa de lançar mão à água da vida, a esse fluxo perpétuo. De facto, a vida está num perpétuo devir, algo que afeta o vivente e o define como pathos. Em 1992, numa entrevista a Thibault Dhermy, Michel Henry considerava que "filosofia e literatura - mas também pintura, música, toda a forma de arte ou cultura em geral - têm o mesmo «objeto». Só o seu modo de tratamento difere" ${ }^{50}$. Ora, este objeto é

49 Cf., Michel Henry, La barbárie, cap.III, "La science seule: la technique".

50 Michel Henry, Auto-donation. Entretiens et conférences, 65. 
aquilo que se sente, a subjetividade na sua dimensão absoluta. É neste sentido que Michel Henry se afasta da tradição fenomenológica. Com efeito, se esta se preocupou com o "mundo", com o exterior, o "dehors", o autor de Ver $o$ Invisivel quer dar atenção à forma como a vida se dá num vivente.

"A unidade do mundo não pode ser senão fundada na do ego", escrevia Michel Henry em Philosophie et phénoménologie du $\operatorname{corps}^{51}$. É esta convicção, de raiz biraniana, que conduz Michel Henry à defesa de um corpo subjetivo, corpo que se revela originariamente na esfera da imanência absoluta. Se a filosofia se extraviou quando tentou compreender os seres transcendentes e, por conseguinte, o corpo objetivo, é altura de regressar à convicção de Biran, ou seja, a esse corpo absoluto que é o corpo subjetivo. Ora, nada se compreenderá da noção de arte em Michel Henry se não se tomar em consideração a "experiência interna transcendental", quer dizer, a subjetividade do humano e a forma como ela se revela no ego.

\section{REFERÊNCIAS BIBLIOGRÁFICAS}

Chalumeau, Jean Luc. As teorias da arte. Lisboa: Instituto Piaget, s/d.

Farago, France. A arte. Porto: Porto Editora, 2002.

Heleno, José Manuel. O lugar da utopia. Lisboa: Fim de Século Editores, 2000.

Henry, Michel. Auto-donation. Entretiens et conferences. Paris: Beauchesne, 2004. Henry, Michel. De l'art et du politique. Phénoménologie de la vie. Tome III. Paris: PUF, 2004.

Henry, Michel. Voir l'invisible. Sur Kandinsky. Paris: Quadrige/PUF, 2005.

Henry, Michel. Philosophie et phénoménologie du corps. Paris: PUF, 2006.

Henry, Michel. La barbárie. Paris: Quadrige/PUF, 2008.

Henry, Michel. Palavras de Cristo. Lisboa: Edições Colibri, 2003.

Husserl. A Crise das ciências europeias e a fenomenologia transcendental. Uma introdução à filosofia fenomenológica. Lisboa: Centro de Filosofia da Universidade de Lisboa - Phainomenon, 2008.

Kandinsky. De lo Espiritual en el Arte. Barcelona: Barral - Labor, 1983.

Kojève, Alexandre. Las pinturas concretas de Kandinsky. Madrid: Editorial Abada, 2007.

Matisse, Henry. Escritos e reflexões sobre arte. Lisboa, Editora Ulisseia, s/d.

Ortega y Gasset, José. A desumanização da arte e outros ensaios de estética. Coimbra: Almedina, 2003.

Pessoa, Fernando. Obras em prosa. Vol. 2. Lisboa: Europa-América, 1986.

51 Op., cit., 46. 
(Página deixada propositadamente em branco.) 